\title{
Peripheral Arterial Coil Embolization for Hepatic Arteriovenous Malformation in Osler-Weber-Rendu Disease; Useful for Controlling High Output Heart Failure, but Harmful to the Liver
}

\author{
Kenichi Hisamatsu, Masayuki Ueeda, Masaharu Ando, Kazuko Koike, Noriyuki Matsuo, Kazunori Matsu-URA, \\ Hisashi Ueda, Mamoru Hirohata and Masanobu ImaI
}

\begin{abstract}
A 55-year-old Japanese housewife, who had Osler-Weber-Rendu disease, was admitted to our hospital because of frequent epistaxis and worsening exertional dyspnea. The computed tomography and hepatic arteriography revealed large hepatic arteriovenous malformation, which was considered to be the leading cause of her high output heart failure. Two series of hepatic arterial coil embolization procedures were performed to reduce hepatic shunt flow. They temporarily improved her cardiac condition, but gradually induced progressive hepatic failure due to intrahepatic cholangitis. Hepatic dysfunction restricted her quality of life and lead to a fatal clinical course one year after the second coil embolization.

(Internal Medicine 38: 962-968, 1999)
\end{abstract}

Key words: hereditary hemorrhagic telangiectasia (HHT), arteriovenous malformation (AVM), cardiac failure, intrahepatic cholangitis, hepatic dysfunction

\section{Introduction}

Hereditary hemorrhagic telangiectasia (HHT), also known as Osler-Weber-Rendu disease, is an autosomal dominant hereditary disorder, characterized by epistaxis, mucocutaneous telangiectasia, and arteriovenous malformations (AVMs) in multiple organ systems (1). The linkage analysis demonstrated that the disease gene was mapped to chromosome 9q33-q34 (2) and 12q11-q14 (3), with the mutations in the endoglin gene (4) or activin receptor-like kinase 1 gene (5). Arteriovenous malformations usually occur in the lungs, brains, kidney and gastrointestinal tract, but hepatic involvement is relatively rare $(1,6)$. In this reported case of HHT, the patient had a large hepatic arteriovenous malformation, which lead to high output heart failure. Two series of hepatic arterial coil embolization improved both her cardiac status and epistaxis, but they lead to gradually progressive hepatic failure due to intrahepatic cholangitis. Hepatic dysfunction restricted her quality of life and lead to a fatal clinical course one year after the second coil embolization.

\section{Case Report}

A 55-year-old Japanese housewife was admitted to our hospital because of exertional dyspnea and epistaxis. She had been given a diagnosis of HHT at the age of 44 due to frequent epistaxis and telangiectasia. One unit of packed red cell blood (200 ml) was transfused because of anemia, which caused posttransfusion hepatitis at the age of 40 . Her family history revealed that her mother and elder sister had also suffered from HHT. Her father died of hepatocellular carcinoma. During the last several years, she had complained of worsening shortness of breath and palpitation on exertion. Cardiomegaly was also noted on the chest X-ray. Because of more frequent epistaxis and worsened exertional dyspnea since April 1997, she was admitted to our hospital on May 26, 1997.

Upon physical examination at her first admission, her weight was $44 \mathrm{~kg}$ and her height was $148 \mathrm{~cm}$. Multiple telangiectatic lesions on the lips, tongue and on the top of the fingers were noted. A grade 4/6 pansystolic ejectional type murmur was audible at the apex. Bruits were heard widely on the epigastrium. No rhonchi were audible in the bilateral lung fields. Hepatomegaly, extending 3 centimeters below the right costal margin and 8 centimeters below the xiphoid was noticed on

From the Department of Internal Medicine, Mitoyo General Hospital, Kagawa Received for publication August 26, 1998; Accepted for publication June 22, 1999

Reprint requests should be addressed to Dr. Kenichi Hisamatsu, the Department of Internal Medicine, Mitoyo General Hospital, 708, Himehama, Toyohamacho, Mitoyo-gun, Kagawa 769-1695 
abdominal palpation. The liver had a smooth surface, a dull edge and a soft elasticity without any tenderness. Splenomegaly was not observed. No pretibial edema was observed on the lower extremities.

The blood examination at admission (Table 1) showed macrocytic anemia with a normal white cell and thrombocyte count, mildly elevated total bilirubin concentration, $\gamma$ glutamyltranspeptidase and decreased choline esterase and plasma protein concentration. A serological test for hepatitis $\mathrm{C}$ viral antibody was positive.

The chest X-ray examination revealed cardiomegaly (cardiothoracic ratio, 67\%) with moderate pulmonary congestion (Fig. 1). The electrocardiogram revealed a normal sinus rhythm ( 86 beats per minute), a left atrial overload and a high voltage of QRS in the left pre-cordial leads (Fig. 2). The echocardiography showed dilation and hyperdynamism of the left ventricle with an end-diastolic dimension of $60 \mathrm{~mm}$, an ejection fraction of $66 \%$ and a cardiac output of $9.6 \mathrm{l} / \mathrm{min}$. The color Doppler flow mapping showed mild mitral regurgitation. The right atrium and ventricle were normal size. The estimated right ventricular systolic pressure of $35 \mathrm{mmHg}$, calculated us- ing the velocity of tricuspid regurgitation, revealed a slightly elevated pulmonary arterial pressure. The abdominal dynamic computed tomographic scans (CT) showed anomalously dilated hepatic vasculatures of the artery and portal and hepatic veins (Fig. 3A). The rapid enhancement effect of the hepatic vein was observed during dynamic contrast $\mathrm{CT}$ examination, which indicated arteriovenous malformation in the liver (Fig. 3B). In other organs, such as the brain and lungs, we could not detect any arteriovenous malformation on dynamic CT scans.

Cardiac catheterization, hepatic arteriography and portography were performed to examine her cardiac condition and hepatic vascular malformation, which we assumed to be the leading cause of her high output heart failure. The hepatic arteriogram (Fig. 4A) revealed a markedly enlarged common hepatic artery of $17 \mathrm{~mm}$ in diameter with high blood flow speed, tortuous hepatic arteries and early contrast filling of dilated hepatic veins, indicating large hepatic arteriovenous shunt. The cardiac functional study with a Swan-Ganz catheter revealed a calculated cardiac output of $10.1 \mathrm{l} / \mathrm{min}$, a cardiac index of 7.7 $l / \mathrm{min} / \mathrm{m}^{2}$ and a mean pulmonary wedge pressure of $11 \mathrm{mmHg}$, indicating high output cardiac failure. To reduce large hepatic

Table 1. Laboratory Data on Admission

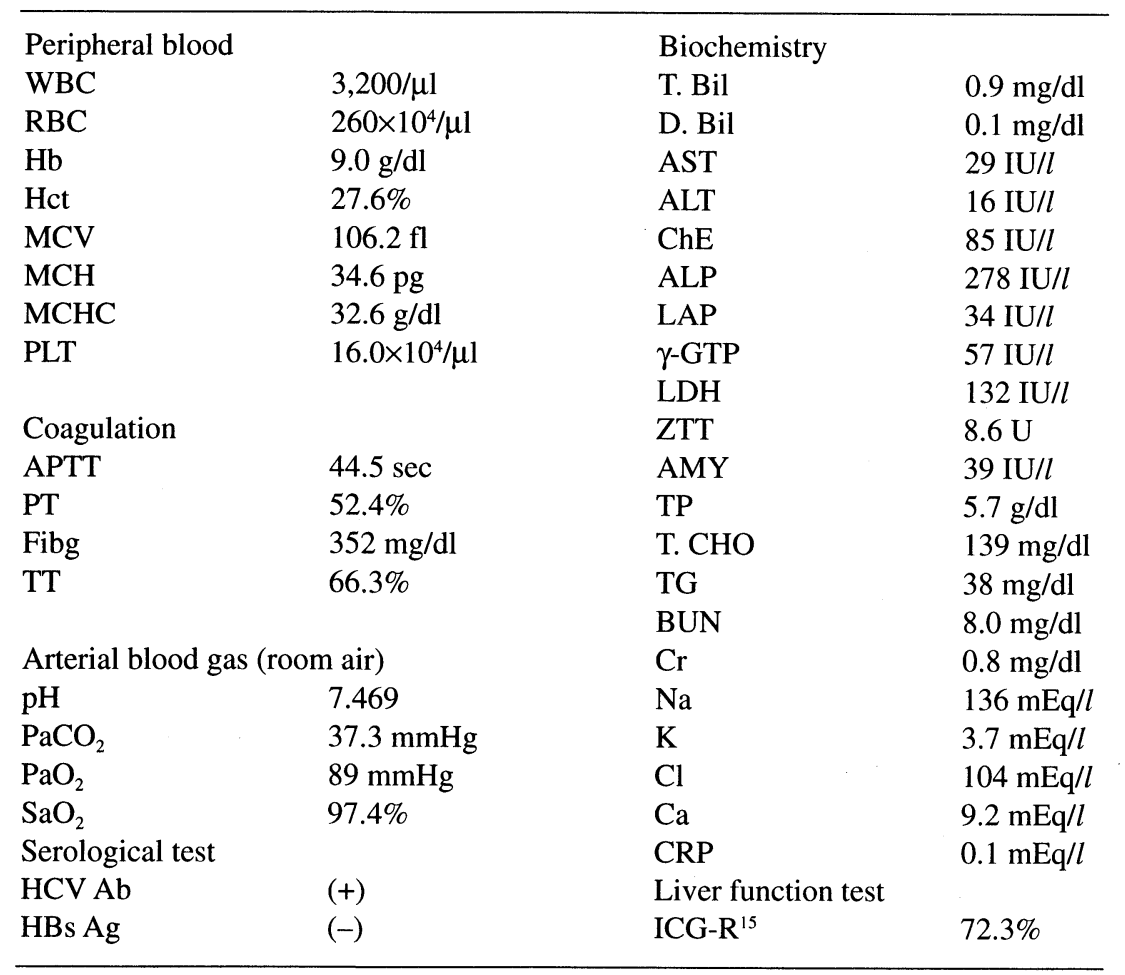

WBC: white blood cell, RBC: red blood cell, $\mathrm{Hb}$ : hemoglobin, $\mathrm{Ht}$ : hematocrit, MCV: mean corpuscular volume, $\mathrm{MCH}$ : mean corpuscular hemoglobin, $\mathrm{MCHC}$ : mean corpuscular hemoglobin concentration, PLT: platelet, APTT: activated partial thromboplastin time, PT: prothrombin time, Fibg: fibrinogen, TT: thrombin time, T. Bil: total bilirubin, D. Bil: direct bilirubin, AST: aspartate aminotransferase, ALT: alanine aminotransferase, ChE: cholinesterase, ALP: alkaline phosphatase, LAP: leucine amino peptidase, $\gamma$-GTP: $\gamma$ glutamyltranspeptidase, LDH: lactate dehydrogenase, ZTT: Zinc sulfate turbidity test, AMY: amylase, TP: total protein, T. CHO: total cholesterol, TG: triglyceride, BUN: blood urea nitrogen, $\mathrm{Cr}$ : creatinine, CRP: c-reactive protein, ICG: indocyanine green. 


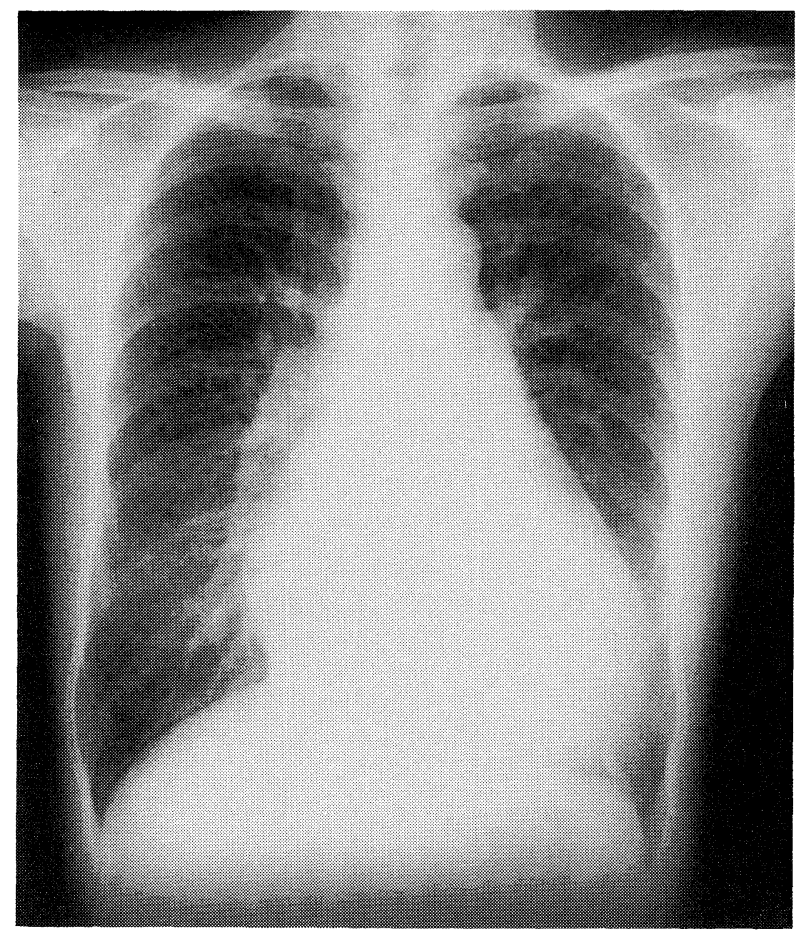

Figure 1. Chest X-ray examination on the initial admission, showing cardiomegaly with moderate pulmonary congestion.

arteriovenous shunt flow, we chose hepatic arterial coil embolization. Full medical information about the estimated beneficial and adverse effects was explained to the patient and her family, as an informed consent. They were also informed of another choice of treatment, surgical ligation of the hepatic artery. The patient preferred coil embolization because it is a less invasive procedure. The first percutaneous trans arterial coil embolization was performed on July 3. A Swan-Ganz catheter, connected to a Vigilance ${ }^{\circledast}$ (Baxter, CA USA) continuous cardiac output monitor, was inserted for hemodynamic monitoring during the procedure. A total of 29 Tornade $^{\circledR}$ coils (Target, IN USA), 15 of $10 \mathrm{~mm}-4 \mathrm{~mm}$ (proximal-distal diameter), 4 of $8 \mathrm{~mm}-5 \mathrm{~mm}$ and 10 of $8 \mathrm{~mm}-4 \mathrm{~mm}$ sized coils, were released into the right, middle and left hepatic arteries (Fig. 4B, C). The right and left hepatic arteries were almost completely occluded, but the middle branch was partially obstructed because of an anatomically difficult arterial structure. The continuous cardiac output monitoring showed a $30 \%$ reduction of cardiac output after coil embolization from $15.5 \mathrm{l} / \mathrm{min}$ to 10.7 $\mathrm{l} / \mathrm{min}$. The effect of the first embolization was evaluated by chest X-ray and echocardiography. The cardiothoracic ratio on the chest X-ray, diastolic left ventricular diameters, ejection fraction and cardiac output on echocardiography decreased from $67 \%, 60 \mathrm{~mm}, 66 \%$ and $9.6 \mathrm{l} / \mathrm{min}$, to $58 \%, 56 \mathrm{~mm}, 54 \%$ and 6.4 $l /$ min, respectively (Table 2 ). She complained of epigastralgia for one month, but less frequently for other symptoms such as shortness of breath, palpitation and epistaxis.

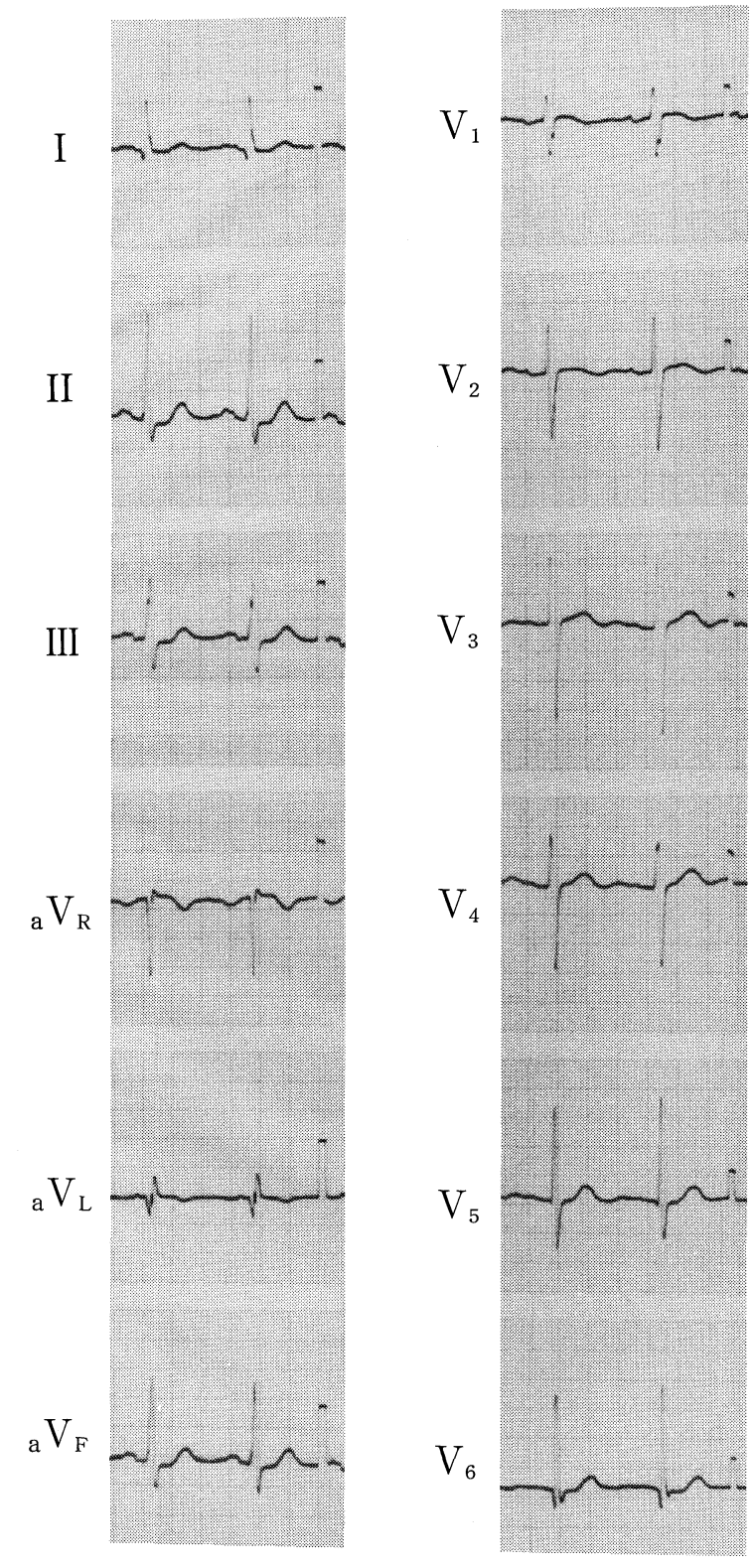

Figure 2. Electrocardiogram on the initial admission, showing a normal sinus rhythm (the heart rate was 86 beats per minute), a left atrial overload and a high voltage of $Q R S$ in the left pre-cordial leads.

Six months later, her chest X-ray showed a reenlarged cardiothoracic ratio of $67 \%$ and pulmonary congestion. Her epistaxis had also become more frequent. The echocardiography revealed re-increased cardiac output. The abdominal ultrasound tomography and Doppler study also showed increased hepatic arterial and venous flow. Her hemoglobin concentration was $9.7 \mathrm{~g} / \mathrm{dl}$, indicating no progression of anemia. She was admitted again on December 12, 1997. The second hepatic angiography was performed to re-examine her hepatic vasculature. The left and right hepatic arteries were partially obstructed, and the shunt flow through the middle hepatic artery, particu- 


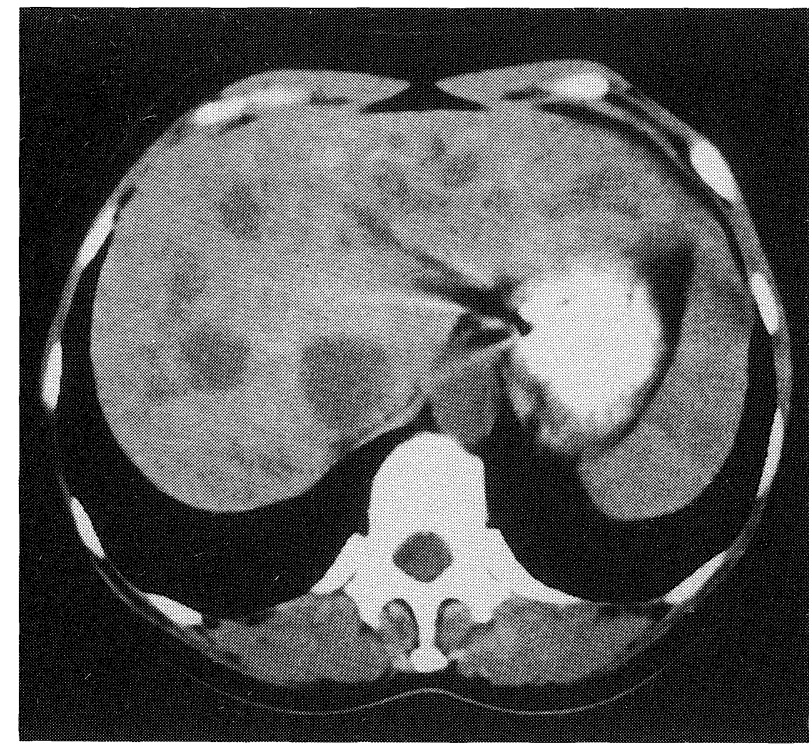

A

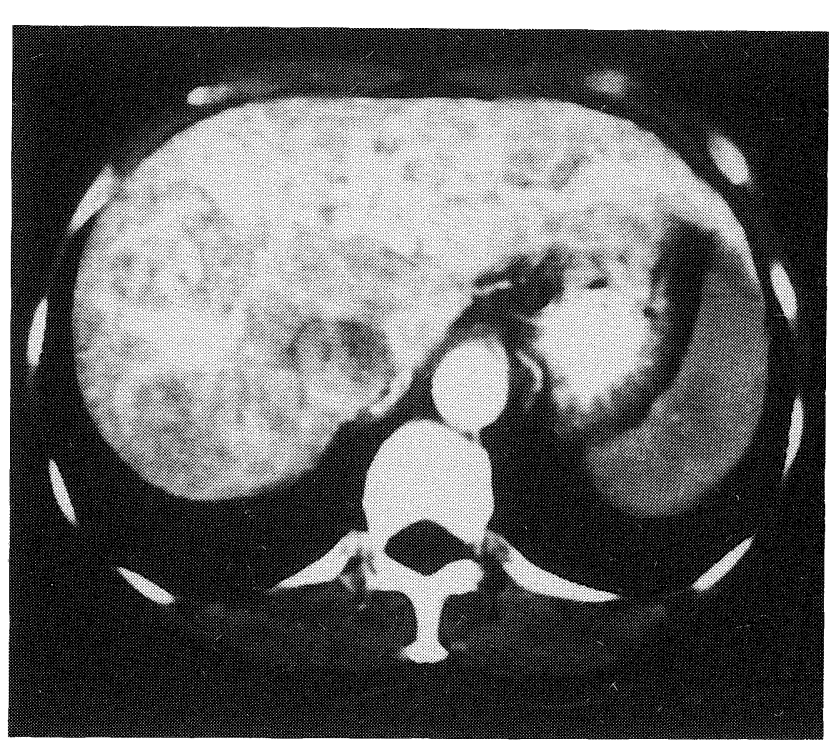

B

Figure 3. Abdominal dynamic CT scans on the initial admission, showing the dilated hepatic artery and portal and hepatic veins (A). The hepatic vein was greatly dilated and quickly enhanced by contrast material only 30 seconds after the start of injection (B).

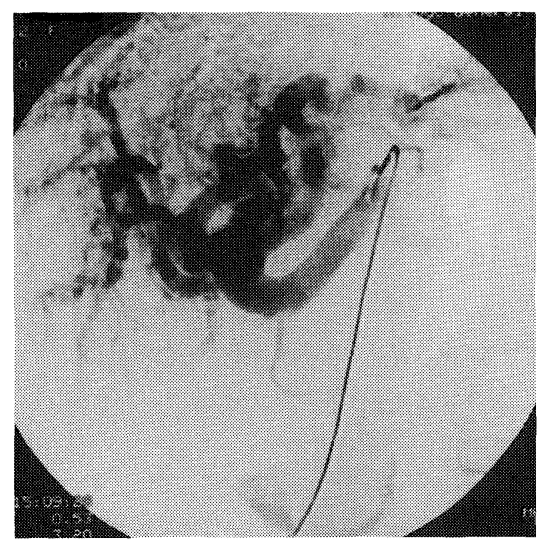

A

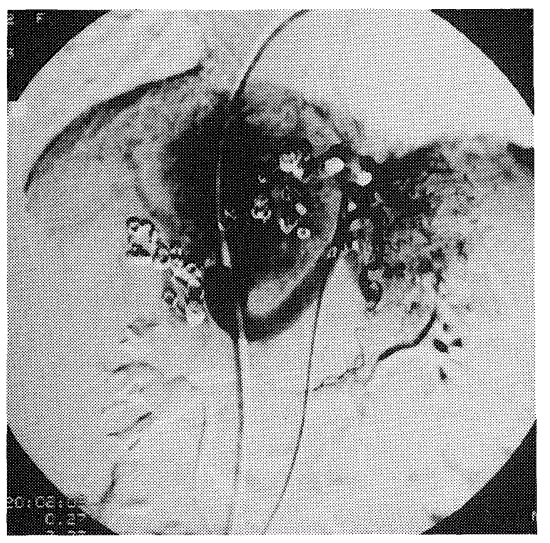

B

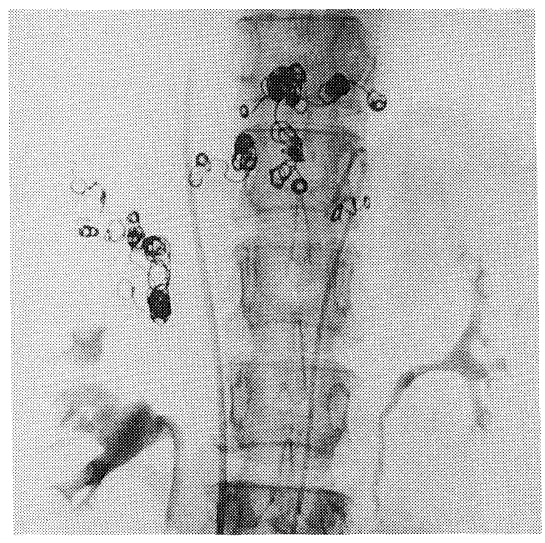

$\mathrm{C}$

Figure 4. Hepatic arteriogram on the initial admission, showing a markedly enlarged common hepatic artery of $17 \mathrm{~mm}$ in diameter (A). All branches of the hepatic artery were almost completely occluded with 29 coils, except for the partially obstructed middle branch $(\mathrm{B}, \mathrm{C})$.

larly around the non-obstructed small branch was increased. Small new collateral vessels from the superior mesenteric artery into the liver were also observed. The second coil embolization was performed on the same day using 19 Tornade coils to obstruct the middle hepatic artery. Nearly complete obstruction of the hepatic artery was achieved. The cardiothoracic ratio, left ventricular end-diastolic dimension and cardiac output were reduced from $67 \%, 57 \mathrm{~mm}$ and $12.4 \mathrm{l} / \mathrm{min}$ to $60 \%, 53$ $\mathrm{mm}$ and $6.6 \mathrm{l} / \mathrm{min}$, respectively (Table 2 ). The patient was dis- charged 19 days after the operation. However, because of prolonged epigastralgia, edema in the face and legs, general fatigue and fever, she was admitted to the hospital for the third time on January 11,1998 . The blood chemistry revealed elevated total bilirubin $(2.5 \mathrm{mg} / \mathrm{dl})$, alkaline phosphatase $(1,099$ IU $/ l$ ), $\gamma$ glutamyltranspeptidase ( $83 \mathrm{IU} / l$ ), reduced choline esterase $(48 \mathrm{IU} / l)$ and total protein concentration $(5.4 \mathrm{~g} / \mathrm{dl})$. Ultrasound abdominal tomography revealed intrahepatic bile duct dilatation in the middle hepatic lobe, indicating intrahepatic 
Hisamatsu et al

Table 2. The Hemodynamic Parameters before and after the Coil Embolization

\begin{tabular}{lllllll}
\hline & & \multicolumn{2}{c}{ 1st embolization (Jul 3/97) } & & \multicolumn{2}{c}{ 2nd embolization (Dec 9/97) } \\
\cline { 3 - 4 } \cline { 6 - 7 } & & pre & post & & pre & post \\
\hline CTR & $(\%)$ & 67 & 58 & & 67 & 60 \\
LVDd & $(\mathrm{mm})$ & 60 & 56 & & 57 & 53 \\
LVDs & $(\mathrm{mm})$ & 38 & 41 & & 32 & 32 \\
EF & $(\%)$ & 66 & 54 & & 82 & 67 \\
CO & $(l / \mathrm{min})$ & 9.6 & 6.4 & & 12.4 & 6.6 \\
\hline
\end{tabular}

CTR: cardiothoracic ratio on chest X-ray, LVDd: diastolic left ventricular diameters, LVDs: systolic left ventricular diameters, EF: ejection fraction, CO: cardiac output on echocardiography. The patient's hemoglobin concentrations were 9.2 and $10.3 \mathrm{~g} / \mathrm{dl}$ at the first and second embolization, respectively.

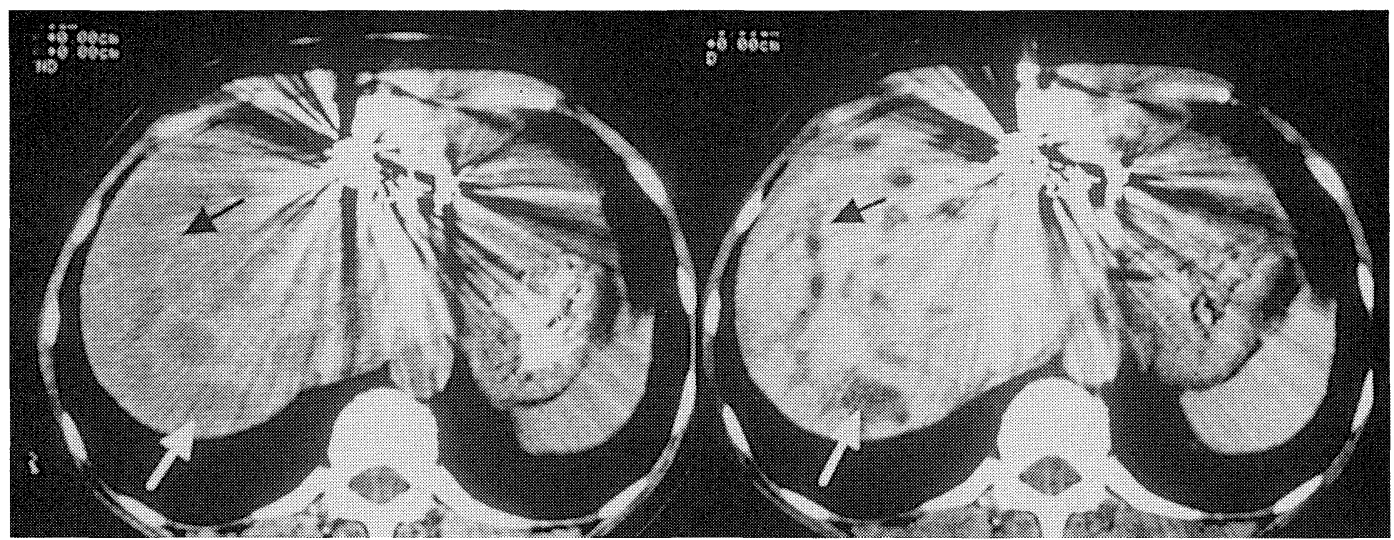

A

$\mathrm{B}$

Figure 5. Computed tomography of the liver, showing anomalous vessel structures in the liver (black arrow and white arrow) (A). The contrast enhancement study revealed non-enhanced channels, indicating enlarged intrahepatic bile ducts (black arrow and white arrow) (B).

biliary tract obstruction and infection. Systemic antibiotics, supplemental albumin and vitamins were administrated to revitalize her hepatic status. Her cholangitis could be controlled by the antibiotics, but she needed regular albumin administration because of her continuous lower albumin concentration.

She was admitted to our hospital for the fourth time because of progressive jaundice and general fatigue on August 31. The blood chemical examination showed further elevated total bilirubin $(7.2 \mathrm{mg} / \mathrm{dl})$, aspartate aminotransferase (131 IU/l), alanine aminotransferase $(82 \mathrm{IU} / l)$, alkaline phosphatase $(1,756$ $\mathrm{IU} / l), \gamma$ glutamyltranspeptidase $(646 \mathrm{IU} / l)$ and $C$ reactive protein $(0.77 \mathrm{mg} / \mathrm{dl})$. It also showed a reduced choline esterase $(35 \mathrm{IU} / l)$ and total protein $(5.9 \mathrm{~g} / \mathrm{dl})$ concentration. The abdominal computed tomography revealed not only large tortuous hepatic vessels but also a markedly enlarged intrahepatic biliary duct (Fig. 5), which indicated biliary duct stagnation. We administrated antibiotics, albumin, vitamins, and frozen flesh plasma but could not revitalize her hepatic function. She died of progressive hepatic failure on November 23, 1998. The necropsy specimen of the liver showed telangiectatic hepatic fibrosis, which is reported to be typical for HHT (7), partial hemorrhage in the parenchyma and bile duct dilatation. In this case, no evidence of piecemeal necrosis indicating type $\mathrm{C}$ viral chronic hepatitis was found in the liver parenchyma.

\section{Discussion}

Hereditary hemorrhagic telangiectasia is a congenital disorder leading to telangiectasia on the skin and mucosal surfaces which bleeds easily, and is frequently associated with the presence of AVMs in multiple organ system (1). The frequency of the presence of AVMs in the liver widely differs among reports, between $8 \%$ and $31 \%(6,8)$. Hepatic involvement sometimes caused high output heart failure (9-23). In the present 
reports, the patient had large hepatic arteriovenous malformation, which caused high output heart failure. Systemic examination in other organs could not detect any other large vascular malformations. Several cases of surgical and interventional treatments of AVMs in the liver have been reported (Table 3). In the late seventies, surgical arterial ligation was the sole choice. Radtke et al described two patients who had undergone an operation in attempt to reduce the size of their large left-to-right shunts and to relieve some of the cardiac burden (10). The reported patients were successfully treated with ligation of the common hepatic artery. In the eighties, embolization of the hepatic artery using metallic coils, gelatin sponge and polymer particle was added to the choice of treatments. In the last several years, because of the progression of interventional radiology, coil embolization has been more frequently selected, but the effects have varied. Zentler-Munro et al chose intervention (the trans-arterial coil embolization) initially, but it was unsuccessful because of the development of collateral circulation (15). In the end, they chose open hepatic artery ligation, which was successful. In the recent reports of five HHT patients with hepatic AVMs, embolization successfully improved their high output heart failure $(22,23)$. Liver transplantation, which is considered to be the fundamental treatment for hepatic AVMs, was first reported in 1995 (17), and several reports followed in $1998(19,20)$. Odorico et al re- ported that their first attempt at coil embolization induced biliary necrosis and hepatic failure, resembling our case report, but they were able to save the patient by liver transplantation (19).

In this case, interventional therapy of transarterial coil embolization was selected to reduce the large intrahepatic arteriovenous shunt flow because it was a less invasive method. The main reason we selected the coil embolization was the patient's preference, but we were also concerned about her basic low hepatic function, excessive perioperative bleeding due to peritoneal telangiectasia, and progressive anemia before operation. When we informed the patient and her family in 1997, there were some affirmative but only a few negative reports about the effects of the coil embolization for AVMs in HHT. We had scheduled a second surgical treatment if the coil embolization failed. Though the abdominal pain persisted for one month, her symptoms, which were related to heart failure and epistaxis, improved remarkably after the first embolization. However, her exertional dyspnea and epistaxis recurred a half year later, due to increased collateral flow around the coil-embolized region of the liver. Vascular regeneration is prominent in a HHT patient. The second hepatic arteriography revealed newly developed collateral vessels not only around the middle hepatic artery but also from the superior mesenteric artery through the liver surface. The second hepatic arterial coil embolization was

Table 3. Summary of Treatments for the Hepatic Arteriovenous Malformation in Osler-Weber-Rendu Disease

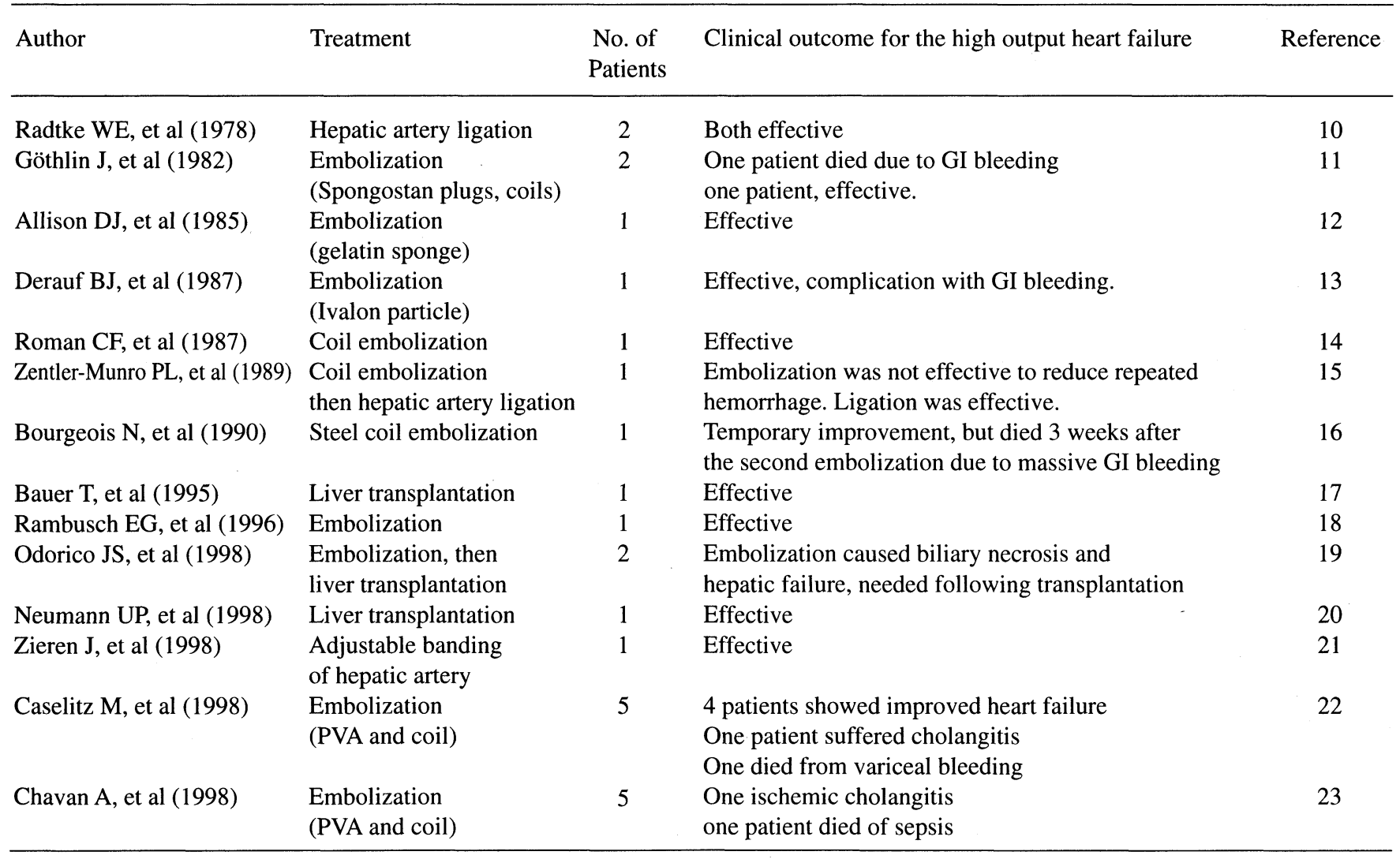

GI: gastrointestinal tract, PVA: poly vinyl alcohol particle. 


\section{Hisamatsu et al}

performed to decrease the middle hepatic arterial flow. It successfully improved her hemodynamic data, but lead to prolonged epigastralgia, intrahepatic cholangitis, and progressive hepatic insufficiency. We suspected that the causes of intrahepatic cholangitis and hepatic dysfunction were; 1) reduction of arterial oxygen supply to hepatocyte, 2) stagnation of the bile duct and 3) reduction of portal venous flow to parenchyma. These events happened due to the mechanical disturbance of portal venous and bile duct flow by the re-shaped tortuous metallic coils in the nearby hepatic arteries. Additional surgical ligation after the second embolism could not be considered because of the low hepatic functional reserve. The recent report of Chavan et al described five cases of successful treatment of HHT by embolization (23). They induced cholangitis in only one case. The main difference from our case is that they embolized the peripheral hepatic arteries and arterioles by polyvinyl alcohol and used large coils to embolize the main hepatic artery. The reshaped coils did not restrict the nearby portal vein or bile duct. The fundamental treatment of AVMs in HHT patient is liver transplantation, but it is quite difficult in Japan because of the social situation. Recently in Japan, we seem to have 2 choices for the treatment of high output failure in the HHT patient, that is; 1) embolization of the hepatic artery; proximal arterial coil embolization and peripheral polymer embolization, to avoid restriction of portal and biliary flow, 2) surgical ligation of the main hepatic artery, which could maintain good portal venous flow into the liver. Peripheral arterial coil embolization might be temporarily useful for high output heart failure, but it is harmful to the liver.

\section{Conclusion}

The high output heart failure due to large hepatic arteriovenous malformation in a patient with Osler-Rendu-Weber disease was treated with hepatic arterial coil embolization. Coil embolization of the peripheral hepatic artery temporarily improved the patient's cardiac function, but was harmful to the liver because of inducted intrahepatic cholangitis and hepatic insufficiency.

\section{References}

1) Haitjema T, Westermann CJ, Overtoom TT, et al. Hereditary hemorrhagic telangiectasia (Osler-Weber-Rendu disease). New insights in pathogenesis, complications, and treatment. Arch Intern Med 156: 714-719, 1996 (see comments).

2) McDonald MT, Papenberg KA, Ghosh S, et al. A disease locus for hereditary haemorrhagic telangiectasia maps to chromosome 9q33-34. Nat Genet 6: 197-204, 1994.

3) Johnson DW, Berg JN, Gallione CJ, et al. A second locus for hereditary hemorrhagic telangiectasia maps to chromosome 12. Genome Res 5: 2128, 1995 .
4) McAllister KA, Grogg KM, Johnson DW, et al. Endoglin, a TGF-beta binding protein of endothelial cells, is the gene for hereditary haemorrhagic telangiectasia type 1. Nat Genet 8: 345-351, 1994.

5) Johnson DW, Berg JN, Baldwin MA, et al. Mutations in the activin receptor-like kinase 1 gene in hereditary haemorrhagic telangiectasia type 2. Nat Genet 13: 189-195, 1996.

6) Korzenik JR. Hereditary hemorrhagic telangiectasia and other intestinal vascular anomalies. Gastroenterologist 4: 203-210, 1996.

7) Daly JJ, Schiller AL. The liver in hereditary hemorrhagic telangiectasia (Osler-Weber-Rendu disease). Am J Med 60: 723-726, 1976.

8) Bernard G, Mion F, Henry L, Plauchu H, Paliard P. Hepatic involvement in hereditary hemorrhagic telangiectasia: clinical, radiological, and hemodynamic studies of 11 cases. Gastroenterology 105: 482-487, 1993.

9) Burckhardt D, Stalder GA, Ludin H, Bianchi L. Hyperdynamic circulatory state due to Osler-Weber-Rendu disease with intrahepatic arteriovenous fistulas. Am Heart J 85: 797-800, 1973.

10) Radtke WE, Smith HC, Fulton RE, Adson MA. Misdiagnosis of atrial septal defect in patients with hereditary telangiectasia (Osler-Weber-Rendu disease) and hepatic arteriovenous fistulas. Am Heart J 95: 235-242, 1978.

11) Göthlin JH, Nordgard K, Jonsson K, Nyman U. Hepatic telangiectasia in Osler's disease treated with arterial embolization. Report of 2 cases. Eur J Radiol 2: 27-30, 1982.

12) Allison DJ, Jordan H, Hennessy O. Therapeutic embolisation of the hepatic artery: A review of 75 procedures. Lancet 1: 595-559, 1985.

13) Derauf BJ, Hunter DW, Sirr SA, Cardella JF, Castaneda-Zuniga W, Amplatz K. Peripheral embolization of diffuse hepatic arteriovenous malformations in a patient with hereditary hemorrhagic telangiectasia. Cardiovasc Intervent Radiol 10: 80-83, 1987.

14) Roman CF, Cha SD, Incarvito J, Cope C, Maranhao V. Transcatheter embolization of hepatic arteriovenous fistula in Osler-Weber-Rendu disease - a case report. Angiology 38: 484-488, 1987.

15) Zentler-Munro PL, Howard ER, Karani J, Williams R. Variceal haemorrhage in hereditary haemorrhagic telangiectasia. Gut 30: 1293 1297, 1989 (see comments).

16) Bourgeois N, Delcour C, Deviere J, et al. Osler-Weber-Rendu disease associated with hepatic involvement and high output heart failure. J Clin Gastroenterol 12: 236-238, 1990.

17) Bauer T, Britton P, Lomas D, Wight DG, Friend PJ, Alexander G. Liver transplantation for hepatic arteriovenous malformation in hereditary haemorrhagic telangiectasia. J Hepatol 22: 586-590, 1995.

18) Rambusch EG, Chavan A, Harms CP, et al. Hereditary hemorrhagic telangiectasia with hepatic involvement and including gastric vessels. A case report. Vasa 25: 352-357, 1996.

19) Odorico JS, Hakim MN, Becker YT, et al. Liver Transplantation as Definitive Therapy for Complications After Arterial Embolization for Hepatic Manifestations of Hereditary Hemorrhagic Telangiectasia. Liver Transpl Surg 4: 483-490, 1998.

20) Neumann UP, Knoop M, Langrehr JM, et al. Effective therapy for hepatic M. Osler with systemic hypercirculation by ligation of the hepatic artery and subsequent liver transplantation. Transpl Int 11: 323-326, 1998.

21) Zieren J, Buttemeyer R, Muller JM. Adjustable "banding" of the hepatic artery in treatment of shunt-induced heart failure in Osler-Rendu-Weber disease. Chirurg 69: 639-641, 1998.

22) Caselitz $M$, Wagner $S$, Chavan $A$, et al. Clinical outcome of transfemoral embolization in patients with arteriovenous malformations of the liver in hereditary haemorrhagic telangiectasia (Weber-Rendu-Osler disease). Gut 42: 123-126, 1998.

23) Chavan A, Galanski M, Wagner S, et al. Hereditary hemorrhagic telangiectasia: effective protocol for embolization of hepatic vascular malformations-experience in five patients. Radiology 209: 735-739, 1998. 